\title{
Locational Preference and Unemployment of Asian-born Immigrant in the U.S. Metropolises
}

\author{
Felix Höschle ${ }^{\mathrm{A}}$, Wadim Strielkowski ${ }^{\mathrm{B}}$, Olga Tcukanova ${ }^{\mathrm{C}}$, Emily Welkins ${ }^{\mathrm{D}}$ \\ Received: October 21, 2014 | Revised: March 7, 2015 | Accepted: June 15, 2015
}

\begin{abstract}
Our paper focuses on the problematique of the locational preferences and unemployment of Asianborn migrants in U.S. metropolises. We employ the data from the 2010 United States Census on mostly Asian-born individuals and run a thorough analysis of immigrants' segregation and placement in 23 U.S. largest cities.

Our results show there are no areas with high unemployment and a high share of Asian-born individuals. Moreover, a relationship between unemployment and the share of foreign-born individuals in the U.S. cities comes through as insignificant. Our results support the thesis that Asian-born migrants are sensitive to the presence of unemployment while looking for the suitable habitat. In addition, it appears that they might avoid areas with disproportionally high unemployment rate on purpose. It also stems from our findings that Asian-born migrants in United States work harder and do longer hours in comparison with the other migrants, which also means that they do not constitute a significant burden for U.S. social welfare. We come to the conclusion that our findings might also hold for other groups of immigrants in major U.S and world's metropolises.
\end{abstract}

Key words: locational preferences, migration, cities, unemployment, welfare, United States

\section{Introduction}

Many geographers and demographers nowadays try to find out why some urban areas (usually located in large metropolises) are more attractive to migrants and foreign-born individuals than other seemingly similar areas (see e.g. Park, Iceland, 2011; Zhang, 2011; Rérat, 2012; MacDonald, Sampson, 2012; Stojsavljević, Pantelić, 2013; Hall, 2013). They are very keen on understanding what exactly forms the migrants' decisions about settling down in certain areas. Migrants' and foreign-born individuals' decisions can be effectively channeled and shaped up by the urban development policies that aim at changing and re-defining certain problematic neighborhoods and areas within the city.

There is a plethora of scientific theories that might provide an insight into migrants' decision-making processes. It becomes apparent that in the case of the majority of migrants, emigration to the U.S. becomes one of the measures how improving their social and economic situation, the process that is very similar, in its nature, to those in the other parts of the world (see Madzevic, et al, 2013). Thence, our paper tests the hypothesis whether there exists a significant correlation between the share of foreign-born (mostly Asian) migrants and the rate of unemployment within U.S. metropolises. Moreover, it appears that metropolitan areas distinguished by low unemployment might yield higher percentage of foreign-born individuals. In order to keep the methodology and the empirical model at a simple level, we use the data on Asian-born individuals residing in the U.S. obtainable from the 2010 U.S. Census.

\footnotetext{
A University of Economics, Prague, Winston Churchill Sq. 4, 13067 Prague 3, Czech Republic; fhoschle@gmail.com

B Charles University in Prague, Smetanovo nabr. 6, 11001 Prague 1, Czech Republic; strielkowski@fsv.cuni.cz

C Faculty of technology management \& innovation, ITMO University, 49 Kronverksky pr., 197101 St. Petersburg, Russian Federation; zoa1999@mail.ru

D Independent Researcher; emily@emilywelkins.com
} 
It is well-known that Asian-born immigrants tend to spatially cluster, so if there is a strong previous presence of Asians in a city, it will attract more new Asian migrants (hence, the existence of numerous Chinatowns, Little Koreas, Little Saigons, etc.). Immigrants' clustering or networks formation has long been of a specific interest among scientists. Networking or geographical concentration of migrants from the same source region who are distinguished by the same ethnic origin, background or language is frequently observed in many countries. For instance, there is a large immigrants' community of Tamils in Switzerland, Turks in Germany, Italians in Argentina, Albanians and Bosnians in Italy, Ukrainians in the Czech Republic, Romanians in Italy, or Mexicans in the U.S. While in some cases the formation of immigrants' networks is influenced by the geographic proximity of the host and target countries (i.e. Mexico and U.S. or Albania and Italy), in other cases it might be the language proximity (i.e. Romania and Italy), while there are also cases when one has a reason to believe that there are some other determinants of the process of migrants' networking (see Strielkowski, Welkins, 2015).

It seems that in a large number of cases not only ethnic and language similarities do matter but also spatial characteristics create basis for such networks' formation: for instance, there are Macedonians from Skopje who constitute large immigrants' community in Gothenburg, Sweden or people from the town of Siemiatycze in the north-east of Poland who form a large emigrants' group in Brussels, Belgium. The story of these networks is quite simple: a person from a small town or a rural community moves to the foreign country. After a considerable period of time necessary for settling down this person is followed by the closest family and relatives. Those people are then followed by their closest relatives, friends and neighbors and so on. In such a case local knowledge and "knowing-your-neighbor" which is mostly developed in dense communities where people know each other well appear to be of greater importance than the ethnic or cultural ties.

The rest of our paper is structured as follows: Section 2 outlines a short literature review that describes the factors influencing migrants' decisions when it comes to the selection of urban areas for residing within the cities. Section 3 presents our data and our methods. Section 4 describes our main results and discusses their significance. Finally, section 5 concludes with closing remarks and policy implications.

\section{Migrants in the cities: determinants of spatial selection}

The array of factors that influence migrants' decision on where to settle is broad. Researchers have found various often contradicting determinants that in their mind influence migrants' decisions on settling down in a certain country, region, or the city. Among the first researches explaining the formation of migrants' groups, enclaves and Diasporas was the "Schelling segregation model" that used a mathematical model showing how white and non-white residents moved round and about in the artificial settlement before the balance was finally reached. The status quo situation was very similar to the real-life segregation of white and non-white population in U.S. metropolises such as Philadelphia, or Chicago (Crooks, 2010; Baldwin, et al., 2013).

Most of the studies come to the conclusion that an area with a high share of foreign-born people tends to attract subsequent migrants (see e.g. Zavodny, 1997; Clark, Blue, 2004; Park, Iceland, 2011). Several research papers from the late 1990 os hypothesize that there is likely a relation between immigration and the generosity of the social welfare system (see Borjas, 1999). Migrants analyze their economic opportunities when they make their decisions about where to settle down and chose the highly-ranked opportunity in the list of all available alternatives.

Taking all of the above into account, it makes sense that many researchers found negative or insignificant correlations between unemployment and the share of foreign-born population in many urban areas that were the subject of their analysus. Åslund (2005), Jaeger (2000), Glaeser and Shapiro (2003), Glaeser et al. (2006), Zhang (2011), Glaeser (2011), or Otto and Steinhardt (2014) all concluded that unemployment and segregation of migrants are not related. On the contrary, Åslund (2005) states that foreign-born residents prefer to stay in the areas with low unemployment. Additionally, he demonstrates that migrants that move around their new country of residence are likely to be attracted by the areas with more employment opportunities. These results might mean that unemployment is not the only important factor for migrants' decision-making and the selection of the place to reside. Furthermore, Åslund (2005) states that migrants originating from different countries also have different sensitivities towards unemployment. Taking the U.S. into consideration, he found people from the Middle East and South America were the most sensitive to the situation on the local labour markets (Åslund, 2005). Glaeser and Shapiro (2003) showed that in the 1990s U.S. cities yielding the unemployment rates of 10 percent and higher were growing at a rate rates below 3 percent, while the cities with unemployment rates below 5 percent were growing with a rate of about 21 percent. They explain their results by using the argument that the areas with robust labor markets might have a general appeal and are therefore more attractive and productive. 
While many studies find that high employment rates attract migration from both abroad and other less-developed and rural areas within the U.S., there are other studies that come up with different results. For instance, Zavodny (1997) found out that high unemployment attracted incoming migration while the economy dominated by manufacturing businesses potential migrants. Since those outcomes seemed to be illegitimate, Zavodny (1997) believed that they were not robust. However, she denied that there was a relationship between unemployment and immigration and claimed that only migrants shape up their decision about settling down based on their expectations on the number of their countrymen they expect to meet across in the desired areas.

In a case when migrants move to the areas distinguished by lower unemployment, the obvious conclusion would be that they are not a priori interested in social welfare and family support programs, but rather prefer to find employment and make their own salary. The majority of researchers are in accord that migrants prefer to live in the areas that are also inhabited by their countrymen of people of the same origin or religious background. When it comes to the relationship between unemployment and immigration, most of the researchers think that migrants tend to incline towards areas with favorable economic opportunities and low unemployment rates. However, there are also researchers that report the results indicating an existence of the positive relationship between unemployment and immigration.

\section{The data and the model}

In order to conduct an empirical analysis executed in this paper, we employed the data from the United States 2010 Census. The data was initially collected by the Census Bureau and contains a number of useful variables including the total number of foreign-born individuals, race, gender, population size, age, housing, employment status, and the like. The data can be employed to conduct the comprehensive analysis of social and economic relationships for the United States and for the given year. The first Census was conducted in 1790 and since then there was a census run every 10 years. In 2010, the Census Bureau mailed 98 million forms to households in the US and delivered 22 million extra forms intended for the households that could not be reached by regular mail. Due to this massive effort, the data set contains detailed information on a very high sub-set of the U.S. population. There exist several summary files for the data and the data used for the empirical analysis described in this paper are sample data from summary file 3 derived from the long-form survey.
In order to support or to reject our hypothesis that aims to test whether the unemployment in a certain region is determined by the migrants' decision about which region of the U.S. they want to settle down, we created an empirical model with two main variables. The first variable $(\Delta A)$ describes the percentage of Asian-born individuals and residing in a certain region. Thence, we divided the total number of Asianborn individuals in a region $\left(A_{i}\right)$ by the corresponding total population (TP). The following relationship (1) describes the results of the described outcome:

$$
\Delta A=\frac{A_{i}}{T P}
$$

The second variable created for our empirical analysis is the unemployment rate $\left(U_{r}\right)$. In order to create this variable, we subtracted the sum of employed people $(E)$ from the labor force $(L F)$, and then divided the obtained result by the total amount of people present in the labor force (TA). This procedure can be described by the following formula (2):

$$
U_{r}=\frac{L F-E}{T A}
$$

Following these procedures, we run the scatter plot relationship between the two above-mentioned variables $\Delta A$ and $U_{r}$.The obtained graphical relationship enables us to identify the interdependence between these two variables in question and to make some conclusions about their relationship and about the significance of this relationship.

\section{Main results and discussions}

The scatter plot described in the previous sub-chapter demonstrates a slightly positive correlation between unemployment rate (x-axis) and the share of Asianborn migrants (y-axis). The plot itself is depicted in Figure 1.

One can see that the vast majority of the dots are located at the bottom left part of the scatter plot. The other dots can be found either at the upper left side or at the lower right side. There are no dots at the upper right side. These results mean that there are either areas with low unemployment rate and low share of Asian-born individuals, areas with low unemployment and high share of Asian born individuals, or areas with high unemployment rate and low share of Asian-born individuals. It is quite surprising that there are no areas with both high unemployment and high share of Asian-born individuals.

In our analysis, every dot in the scatter plot possesses the same importance for our trend curve. A single person settling down in a small city where she/he is the 


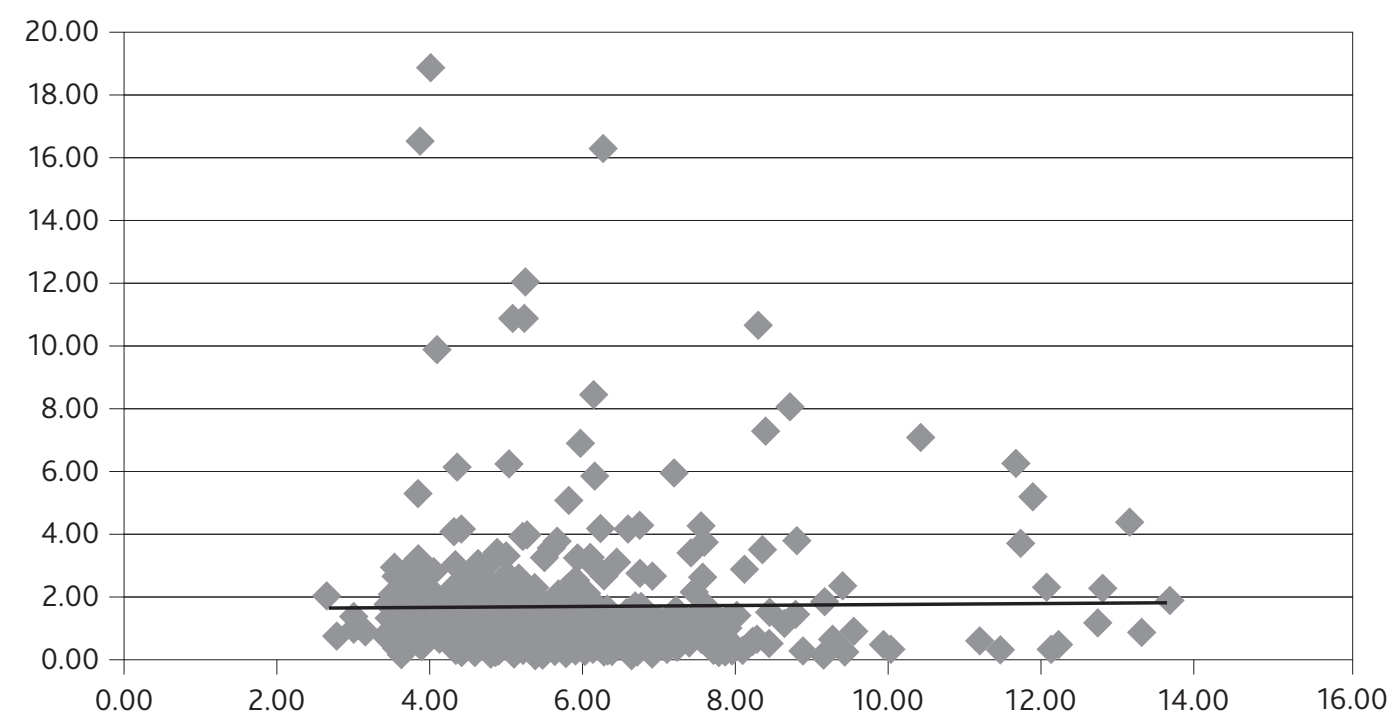

Figure 1. Unemployment and foreign-born individuals (U.S. 2010 Census). Note: y-axis: share of Asian-born individuals; $x$-axis: unemployment rate

only Asian-born migrants is equally important for the trend curve as, say, 300.000 Asian-born migrants that have decided to settle down in some other area.

Of course, this leads to a certain bias in the trend curve. In order to avoid this bias one should look at a second scatter plot that only takes into account top 10 areas with the highest total amount of Asian-born residents. This other scatter plot reports the data for the 36 percent of the Asian-born individuals in the largest U.S. cities. The resulting scatter plot demonstrates a very strong negative correlation between unemployment and the share of Asian-born individuals (see Figure 2).

Both scatter plots yield a holistic and comprehensive picture. First, there appear to be no U.S. are- as with both high unemployment and high share of Asian-born migrants. When one looks at the second scatter plot (Figure 2), it becomes apparent that there is a negative correlation between unemployment and the share of foreign-born migrants.

Our findings appear to bring evidence about the Asian-born migrants' sensitivity to the existing unemployment in their choice of areas for settling down within the large U.S. cities. It appears that they especially avoid areas with exceptionally high unemployment rates. We think that it seems rational to assume that this kind of behavior is similar for other groups of migrants as well as for other channels of rural-urban migrations in both the United States and in the other parts of the world (see e.g. Pantelić et al., 2011). In ad-

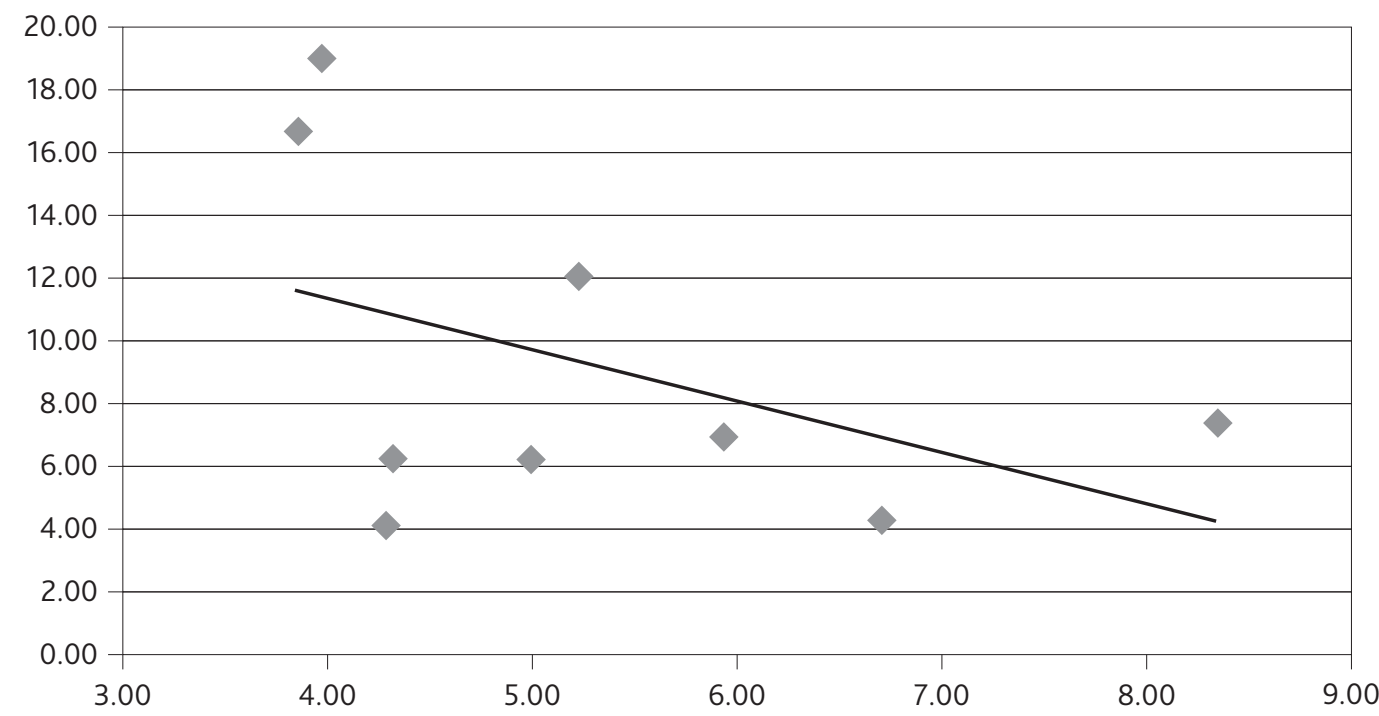

Figure 2. Unemployment and foreign-born individuals (U.S. 2010 Census, areas with highest numbers of Asian-born individuals). Note: $y$-axis: share of Asian-born individuals; $x$-axis: unemployment rate 
dition, it might be shown that Asian-born migrants in United States and Canada tend to work harder than the representatives of other migrant groups and that they rarely rely upon any form of social welfare (see e.g. Belanger and Rogers, 1992; or Almond et al., 2013).

Even though they should be taken with care, our findings seem to be relevant for a number of reasons. Nowadays, lots of changes are happening in the world economy. Many jobs are outsourced to other countries or even continents using modern communication tools and information technologies as well as the opportunities provided by the Internet. Thence, it becomes very important for an individual on a job market to demonstrate skills that might positively distinguish her or him from the others. Education presents one of the most important foundations for being able to obtain and exert such skills. More developed areas with low unemployment tend to boast by better education systems and thence it makes more sense for migrants to choose these areas for residing.

Moreover, migrants might be wise in avoiding areas with high unemployment. Not that it is cumbersome to find employment in these areas, but the influence and the effect of the bad neighborhood might also be prevalent. This might be illustrated on the example when the child growing up in a neighborhood with a large share of unemployed people might get used to the fact that being unemployed means no harm and is, in fact, very natural. This belief might lower her or his efforts at school and therefore exert a negative influence on her or his future grown-up life, job market perspectives and potential earnings. Desperation that is very often prevalent in many low-income residential areas tends to hold people down and prevents them from developing their creativity and potential.

\section{Conclusions and policy implications}

Even though our results seem to be corroborated up by the real-life evidence, there exist some arguments that might cast doubt on their quality and significance. First, it comes through as quite surprising that we found a positive correlation in the first scatter plot. Furthermore, the unemployment data we used did not take into account the fact that when migrants had initially moved to the new place of residence, the unemployment rate used to be different. This fact could undermine the results of the correlation and imply that it does not mean anything. The question is whether the today's unemployment rate can really be a factor for an immigrant's decision made in the past.

Moreover, it is not quite obvious which direction predetermines the possible causation. One can argue that it very well may be that migrants do not choose an area with low unemployment but induce low un- employment (or higher unemployment) in certain areas by stimulating the local economy with their skills. For instance, immigration might lead to higher density of population which could in turn have positive effects on the economy and the employment situation in the certain region or a city.

It also has to be acknowledged that low unemployment rates might just be an indicator of a good and lively labor market. Therefore, immigrants do not come due to low unemployment rate but better labor market opportunities.

In spite of all those concern, both the results obtained from using the U.S. 2010 Census data and the common sense indicate that Asian-born migrants and most likely all migrants in general tend be inclined to moving into areas with high employment and low unemployment. Although our results should be taken with care, they might provide grounds for an existence of a clear relationship that are apparent from the second scatter plot provide an indication that U.S. metropolises with their vast employment opportunities act like magnets and attract migrants from far and away. This process helps to level out the regional disparities and differences and to sustain a balanced development and growth throughout the vastly-populated urban areas.

\section{References}

Almond, D., Edlund, L., Milligan, K. 2013. Son preference and the persistence of culture: evidence from South and East Asian Immigrants to Canada. Population and Development Review 39-1, 75-95.

Åslund, O. 2005. Now and forever? Initial and subsequent location choices of immigrants. Regional Science and Urban Economics 35-2, 141-165.

Baldwin, W. C., Boardman, J. T., Sauser, B. J. 2013. Expanding a system of systems model with the Schelling segregation model. Systems Research and Behavioral Science 30-1, 65-75.

Belanger, A., Rogers, A. 1992. The internal migration and spatial redistribution of the foreign-born population in the United States: 1965-70 and 19758o. International Migration Review, 1342-1369.

Borjas, G. J. 1999. The economic analysis of immigration. Handbook of labor economics 3, 1697-1760.

Clark, W. A., Blue, S. A. 2004. Race, class, and segregation patterns in US immigrant gateway cities. Urban Affairs Review 39-6, 667-688.

Crooks, A. T. 2010. Constructing and implementing an agent-based model of residential segregation through vector GIS. International Journal of Geographical Information Science 24-5, 661-675.

Florida, R. 2003. Cities and the creative class. City \& Community 2-1, 3-19. 
Glaeser, E. 2011. Triumph of the city: How our greatest invention makes US richer, smarter, greener, healthier and happier. Pan Macmillan

Glaeser, E. L., \& Shapiro, J. M. 2003. Urban growth in the 1990s: Is city living back? Journal of regional science 43-1, 139-165.

Glaeser, E. L., Gyourko, J., Saks, R. E. 2006. Urban growth and housing supply. Journal of Economic Geography 6-1, 71-89.

Glitz, A. 2012. The labor market impact of immigration: A quasi-experiment exploiting immigrant location rules in Germany. Journal of Labor Economics 30-1, 175-213.

Hall, M. 2013. Residential integration on the new frontier: Immigrant segregation in established and new destinations. Demography 50-5, 1873-1896.

Jaeger, D. A. 200o. Local labor markets, admission categories, and immigrant location choice. Manuscript, College of William and Mary.

MacDonald, J., Sampson, R. J. 2012. The World in a City Immigration and America's Changing Social Fabric. The ANNALS of the American Academy of Political and Social Science 641.1, 6-15.

Madzevic, M., Toshevska-Apostolovska, B., \& Iliev, D. 2013. A process of demographic and economic polarization in the Republic of Macedonia. Geographica Pannonica 17-2, 46-53.

Otto, A. H., Steinhardt, M. F. 2014. Immigration and election outcomes-Evidence from city districts in
Hamburg. Regional Science and Urban Economics 45, 67-79.

Pantelić, M., Ivkov-Džigurski, A., Ivanović, L., Dragin, A., Blešić, I. 2011. Unemployed persons in border municipalities of Northern Banat in Serbia. Geographica Pannonica 15-1, 16-26.

Park, J., Iceland, J. 2011. Residential segregation in metropolitan established immigrant gateways and new destinations, 1990-2000. Social Science Research 40-3, 811-821.

Rérat, P. 2012. The New Demographic Growth of Cities the Case of reurbanisation in Switzerland. Urban Studies 49-5, 1107-1125.

Stojsavljević, R., Pantelić, M. 2013. The influence of the refugees on age structure in immigration municipalities in Vojvodina (Serbia). Geographica Pannonica 17-1, 26-31.

Strielkowski, W., Welkins, E. 2015. Migration Networks in the OECD Countries. Mediterranean Journal of Social Sciences 6-2, 501-505.

Wozniak, A., Murray, T. J. 2012. Timing is everything: Short-run population impacts of immigration in US cities. Journal of Urban Economics 72-1, 60-78.

Zavodny, M. 1997. Welfare and the locational choices of new immigrants. Economic and Financial Policy Review (Q II), 2-10.

Zhang, J. 2011. Tipping and Residential Segregation: A Unified Schelling Model. Journal of Regional Science 51-1, 167-193. 